\title{
Impact of a multidisciplinary pain management program on patient care utilization and cost of care
}

\author{
Daniel D Maeng \\ Kelly Baylor \\ John B Bulger \\ John J Han
}

Department of Epidemiology and Health Services Research, Geisinger,

Danville, PA, USA
Correspondence: Daniel D Maeng Department of Epidemiology and Health Services Research, Geisinger, 100N Academy Ave M.C. 44-00, Danville, PA 17822, USA

Tel + I 5702141688

Email ddmaeng@geisinger.edu
This article was published in the following Dove Press journal: Journal of Pain Research

Objective: Chronic pain is a highly prevalent and costly condition with few proven treatment options. Since 2014, Geisinger's Department of Pain Medicine has implemented the Multidisciplinary Pain Program (MPP), which consists of a 3-day educational seminar followed by 12 months of comprehensive care. This study examines the impact of MPP on care utilization and cost between 2014 and 2016 .

Methods: A retrospective health insurance claims data analysis covering a 3-year period between January 2013 and December 2016. Among all patients referred to MPP during the period, a subset of those who were Geisinger Health Plan (GHP) members was identified (113 patients). Those who were GHP members and were referred to MPP after December 2016 served as the contemporaneous comparison group (69 patients). GHP's claims data for the corresponding period were analyzed on a per-member-per-month (PMPM) basis.

Results: MPP was associated with US\$754 PMPM reduction in total cost of care including prescription drug costs $(P=0.014)$ and US $\$ 846$ reduction in total medical cost excluding prescription drugs $(P=0.006)$. These cost savings were attributable to reductions in utilization of high-end diagnostic imaging (52 per-1,000 members-per month; $P=0.015$ ) and acute inpatient admissions (20 per-1,000 members-per month; $P=0.086$ ).

Conclusion: Patients enrolled in MPP were less likely to use expensive diagnostic imaging and experienced fewer hospitalizations, resulting in total cost of care savings. These findings are consistent with the expectation that MPP improves health outcomes among patients suffering from chronic pain.

Keywords: chronic pain, persistent pain, multidisciplinary, utilization, cost of care, claims data

\section{Introduction}

Chronic or persistent pain is a highly prevalent condition affecting all segments of the adult population, often requiring costly care that does not effectively improve patient outcome. ${ }^{1}$ A recent report has indicated there are over 100 million people who suffer from chronic pain in the US. ${ }^{2}$ More specifically, analysis from the 2012 National Health Interview Survey estimated that over 25 million (11.2\%) adults suffer from daily pain, with 14.4 million (6.4\%) reporting "a lot of pain" daily. ${ }^{3}$ The accumulated cost of care for chronic pain care ranges from US\$560 to $\$ 635$ billion annually, which is greater than the annual cost of care for diabetes, coronary artery disease, stroke, and cancer combined. ${ }^{1}$

Care for chronic pain patients can be problematic, often characterized by miscommunication and misunderstandings due to a lack of common terms and definitions, and realistic expectations. Moreover, pain is a subjective experience, requiring patient's self- 
report. ${ }^{4}$ Providers are often dependent on patient's imprecise recall and biased perception between visits to gauge disease severity and treatment progress, which may produce a vague and distorted picture from which to develop a treatment plan. ${ }^{5}$ Furthermore, lack of timely access to symptom severity data limits clinicians' ability to effectively manage patients and optimize long-term treatment regimens.

To meet this challenge, a new model of care management that addresses the root cause of chronic pain is needed. Geisinger has developed and implemented the Multidisciplinary Pain Program (MPP) to meet this challenge in 2014. MPP is an outpatient program developed by Geisinger's Department of Pain Medicine and has been implemented in Geisinger's main outpatient comprehensive pain center located in Danville, Pennsylvania, USA. This study seeks to examine the impact of the MPP program on total cost of care, health care utilization, and prescription opioid use during the 12-month period following the MPP enrollment and beyond.

\section{Background}

Geisinger is a large integrated health care delivery system currently serving more than three million residents throughout 45 counties in central, south-central, and northeast Pennsylvania. Geisinger consists of $\sim 1,600$ employed physicians and 13 hospital campuses, as well as a 583,000-member health plan referred to as Geisinger Health Plan (GHP). Approximately, $40 \%$ of Geisinger patients have health insurance coverage through GHP, which is a full-service regional health plan offering commercial, Medicare Advantage, and Medicaid plans.

Geisinger's MPP is an embodiment of the core principles, concepts, and competencies that have been articulated previously $^{6-9}$ and implemented elsewhere in different contexts in limited scope throughout US and beyond in treating patients with various forms of chronic pain. ${ }^{10-13}$ Specifically, MPP is designed around a whole-person model and utilizes a biopsychosocial-spiritual approach to improve function and quality of life for individuals living with chronic pain, thereby leading to lasting, long-term changes in the individuals' physical function as well as in care-seeking behaviors. The overarching goal is to empower patients to take responsibility for their self-care in pain, and to set and monitor improvement goals. MPP includes a team of health care providers and experts comprised of the following: medical pain providers, pharmacists, psychologists, physical therapists, dieticians, pain coaches, and addiction-trained social workers. This team of providers assesses a patient's readiness for change and aids in problem solving to help patients meet their predefined goals and explore options for pain management. Working in collaboration with primary care providers to assure continuity of care, MPP converts the patient's goals into a personalized care plan. During this program, participants are taught how to develop measurable goals and are given the information and skills needed to achieve their desired outcomes.

Patients can be referred to MPP by any health care provider who has access to Geisinger's electronic health records system (Figure 1). While there are no explicit program enrollment criteria, patients with a chief complaint of persistent pain for 6 months or longer; deemed to have increased dysfunction in daily social, vocational, or interpersonal activities; showed no evidence of suicidal ideation or addictive tendencies; and motivated to proceed with a rehabilitation approach for pain management are eligible to enroll in the MPP program. The referred patients then participate in a 3-day multidisciplinary educational class that teaches them self-management skills and enhances patient engagement (Table 1). Upon completion of the class, the patients then receive 12 months of follow-up care through scheduled appointments and phone calls with the MPP team of providers.

\section{Data}

This study was conducted as Geisinger's quality improvement project and therefore was not subject to Geisinger's Institutional Review Board's approval. To ensure patient confidentiality, identifying patient information, such as patient name, address, and contact information, was removed from the final data sets. From Geisinger's electronic health records, 303 patients who were enrolled in MPP between May 2014 and October 2017 (using the first MPP appointment date as the enrollment date) were identified. Among these patients, a subset of patients who were also members of GHP at any point between January 2013 and December 2016 was identified. This date range, applied to the GHP claims data, was chosen to capture as many as 15 months of pre-MPP enrollment claims experiences of the earliest MPP enrollees. This was done to ensure that any pre-intervention trends and baseline patient heterogeneity are adequately accounted and controlled for in the subsequent analyses. This subset of MPP enrollees who were also GHP members (182 patients) thus comprised the final analytic sample.

Among the 182 patients included in the final analytic sample, there were 113 patients who had enrolled in MPP prior to December 2016 (date of the most recent GHP claims data available). This implied that there were 69 patients who had not yet enrolled in MPP as of December 2016 (but even- 


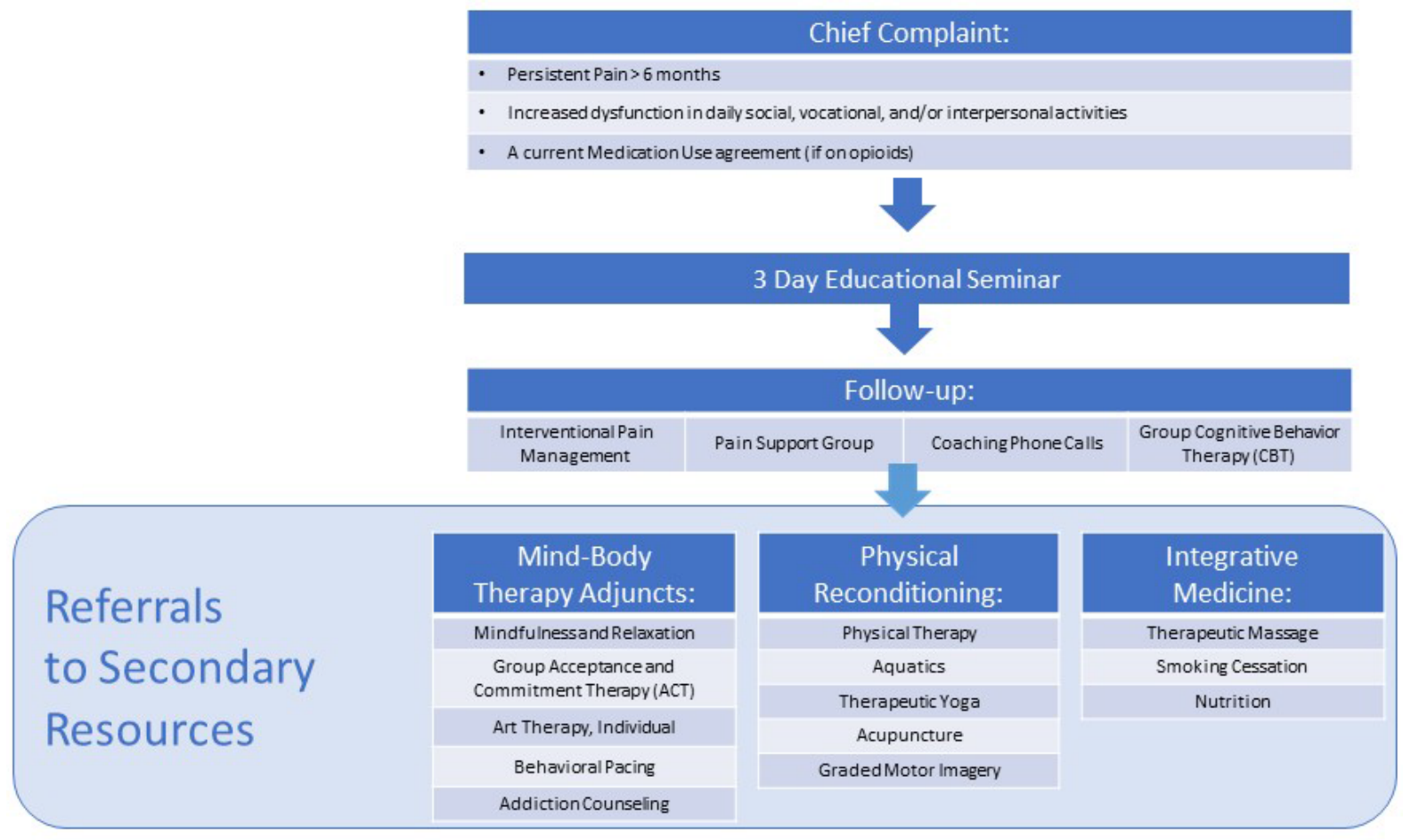

Figure I Multidisciplinary Pain Program workflow overview.

Table I Multidisciplinary Pain Program curriculum

\begin{tabular}{|c|c|c|c|}
\hline Persistent pain education & Physical reconditioning & Life skills & $\begin{array}{l}\text { Behavioral } \\
\text { medicine }\end{array}$ \\
\hline The biopsychosocial model of care & $\begin{array}{l}\text { Yoga-based relaxation and } \\
\text { movement }\end{array}$ & $\begin{array}{l}\text { Financial and medical } \\
\text { support }\end{array}$ & $\begin{array}{l}\text { Progressive muscle } \\
\text { relaxation }\end{array}$ \\
\hline Introduction to acute and chronic pain & Graded motor imagery & Spirituality and pain & Mindfulness \\
\hline $\begin{array}{l}\text { Preventing abuse/misuse of } \\
\text { Prescription pain medication }\end{array}$ & Physical therapy Education & Nutrition & $\begin{array}{l}\text { Persistent pain and } \\
\text { intimacy }\end{array}$ \\
\hline Medication therapy disease & Interventional therapy & Sleep hygiene & Art therapy \\
\hline Management & Education & & \\
\hline Goal setting and review & Behavioral pacing & Horticulture therapy & Recreational therapy \\
\hline
\end{tabular}

tually enrolled at some point between January and October 2017). This latter group of 69 patients thus formed a natural contemporaneous comparison group against which the 113 patients who had enrolled in MPP prior to December 2016 (ie, the intervention group) could be compared.

In addition, because the patients had enrolled in MPP at different points in time, there was variation in how long a patient had been exposed to MPP at any given month during the study period. This implied that a given patient may have zero month of MPP exposure at a given month in the data either because he or she had not yet enrolled in MPP as of that month or because he or she was one of the natural contemporaneous group of 69 that had enrolled in MPP after
December 2016. This study exploited this variation in the length of MPP exposure to estimate the MPP impact on the dependent variables of interest.

From the GHP claims data, each patient's data on total cost of care and acute care utilization were obtained. Total cost of care was defined as total "allowed" amounts - ie, GHP's reimbursement to the provider plus patients' out-of-pocket costs via co-pays, deductibles, and co-insurance, measured on a per-member-per-month (PMPM) basis. Because not all patients had prescription drug coverage through GHP, two separate costs were considered for the analysis: medical cost only (ie, allowed amounts for care and services covered under GHP's medical benefits only) and total cost (ie, medical cost 
plus prescription drug cost for those who had prescription drug coverage through GHP). For acute care utilization, rates of all-cause inpatient admissions and all-cause emergency department (ED) visits were calculated, measured on a per1,000 members-per-month basis.

In addition, rates of high-end diagnostic imaging (defined as CT scans, MRI scans, or positron-emission tomography scans) and frequency of prescription opioid medications were also considered. As mentioned earlier, because not all GHP members had prescription drug coverage through GHP, only those who had prescription drug coverage through GHP (149 out of 182 patients) were considered for the analysis that examined the prescription opioid medication rates. The prescription opioid medication rate was calculated as average frequency of opioid prescription fills per member per month. This rate therefore did not account for morphine equivalence or days supply.

\section{Methods}

The effects of the MPP enrollment on the dependent variables (ie, total cost of care, utilization of acute care and high-end diagnostic imaging, and prescription opioid use) were estimated via a set of multivariate regression models with patient fixed effects to account for unobserved patient heterogeneity (Tables S1, S2, S3). The key explanatory variable was a set of indicators that identified the follow-up period since the initial MPP enrollment (ie, length of the patient's exposure to MPP) in following intervals: 1-6 months, 7-12 months, and $12+$ months. In addition, a $0-1$ binary indicator that identified all follow-up periods regardless of the length of follow-up was also considered to estimate the overall average effect of MPP during the study period.

Other covariates in the regression models were patient age (in intervals of $<40,40-54,55-69,70+$ years), count of comorbid conditions (up to nine: chronic kidney disease, diabetes, asthma, congestive heart failure, COPD, coronary artery disease, hypertension, cancer, and depression), primary payer type (Medicaid, Medicare, or commercial), calendar year (to account for yearly inflation in health care prices), as well as an indicator variable for whether the patient's primary care provider site was designated as a patient-centered medical home. Time-invariant patient attributes, such as patient gender, were not included as covariates because they would be perfectly collinear with the patient fixed effects, which account for any time-invariant patient characteristics over time. A detailed description of the regression model specification is provided in Supplementary material.

The MPP effects were then represented as the difference between the corresponding "observed" and "expected" values obtained from the regression models. "Observed" values for the dependent variables were obtained by calculating the regression-adjusted values for the sample. Then, "expected" values were obtained by setting the key explanatory variables (ie, the MPP enrollment indicator variables) to zero and re-calculating the regression-adjusted values based on the estimated regression model parameters, holding all other parameters constant. The differences between the "observed" and "expected" values therefore represented the MPP effects on the corresponding dependent variables. The standard errors around the estimates were adjusted to account for the repeated observations for the same patient over time.

\section{Results}

The 113 patients who were included in the MPP intervention group for the purposes of this analysis had a mean postintervention follow-up observation of $\sim 10$ months ( $\mathrm{SD}=11$ months). Moreover, 73 out of the 113 patients had at least 12 months of post-MPP follow-up data. Comparing pre-MPP enrollment observations against the post-MPP observations on an unadjusted basis (Table 2), prevalence of certain chronic conditions, particularly chronic kidney disease $(11.7 \%$ vs $5.7 \%)$ and diabetes $(21.7 \%$ vs $16.8 \%)$, was apparently lower among the post-MPP observations. This implied that using regression-adjusted estimates is justified, as there appears to be potential confounders in the data.

MPP enrollment was associated with a significant total cost of care saving of $\sim$ US\$827 PMPM $(P=0.003)$ and medical cost saving of US $\$ 870(P=0.002)$ during the first 6 months following the initial enrollment (Table 3). These initial savings, however, disappeared in subsequent periods, as the estimated cost savings beyond the first 6 months of MPP exposure are not statistically significant $(P>0.1)$. Yet, there was an overall average total cost saving of US\$754 ( $P=0.014$ ) as well as an overall average medical cost saving of US\$846 PMPM $(P=0.006)$ associated with MPP enrollment. These cost savings appeared to be driven by reductions in acute inpatient admission rates (20 admits per-1,000 members-per-month; $P<0.1$; Table 4 ) as well as reductions in high-end diagnostic imaging (52 imaging services per-1,000 members-per month; $P<0.05$; Table 5). Consistent with the pattern observed in the total cost of care, there appeared to be significant and immediate reductions in the inpatient admission and high-end imaging rates during the first 6 months after the MPP enrollment; the magnitudes of these reductions, however, became smaller in subsequent periods. Furthermore, although there was no statistically significant association between MPP enrollment and frequency of 
Table 2 Descriptive statistics

\begin{tabular}{|c|c|c|}
\hline Patient characteristics & MPP exposure $=0$ months $\left(n=4,265^{a}\right)$ & MPP exposure $>0$ months $\left(n=1,739^{a}\right)$ \\
\hline Mean count of acute IP admits (SD) ${ }^{\mathrm{b}}$ & $30(193)$ & $31(207)$ \\
\hline Mean count of ED visits (SD) ${ }^{b}$ & $137(52 \mid)$ & $140(476)$ \\
\hline Mean count of PCP visits (SD) ${ }^{b}$ & $563(791)$ & $476(690)$ \\
\hline Mean count of specialist visits (SD) ${ }^{\mathbf{b}}$ & $578(9 \mid 5)$ & $707(1012)$ \\
\hline Mean count of OP diagnostic imaging (SD) & $96(428)$ & $81(410)$ \\
\hline Mean total allowed (\$PMPM) & $\mathrm{I}, 830(5,165)$ & $2,009(6,026)$ \\
\hline Mean medical allowed (\$PMPM) & I,56I $(5,045)$ & $\mathrm{I}, 688(5,874)$ \\
\hline Mean count of opioid Rx (SD) ${ }^{c}$ & $0.78(1.15)$ & $0.82(0.96)$ \\
\hline Mean age, years (SD) & $49.8(15.5)$ & $51.9(14.5)$ \\
\hline Female (n, \%) & $2,940(68.9)$ & $\mathrm{I}, 06 \mathrm{I}(6 \mathrm{I} .0)$ \\
\hline \multicolumn{3}{|l|}{ Health plan type (n, \%) } \\
\hline Medicaid (n, \%) & $\mathrm{I}, 355(3 \mathrm{I} .8)$ & $704(40.5)$ \\
\hline Medicare (n, \%) & $1,269(29.8)$ & $531(30.5)$ \\
\hline Commercial (n, \%) & $\mathrm{I}, 64 \mathrm{I}(38.5)$ & $504(29.0)$ \\
\hline Has Geisinger PCP (n, \%) & $2,750(64.5)$ & $1,252(72.0)$ \\
\hline In patient-centered medical home (n, \%) & $3,280(76.9)$ & $\mathrm{I}, 497(86.1)$ \\
\hline Mean count of comorbidities (SD) & $1.8(1.6)$ & $1.5(1.7)$ \\
\hline Chronic kidney disease $(n, \%)$ & $501(11.7)$ & $99(5.7)$ \\
\hline Diabetes (n, \%) & $924(21.7)$ & $292(16.8)$ \\
\hline Asthma (n, \%) & $\mathrm{I}, \mathrm{I} 30(26.5)$ & $353(20.3)$ \\
\hline Congestive heart failure (n, \%) & $204(4.8)$ & $65(3.7)$ \\
\hline Chronic obstructive pulmonary disease (n, \%) & $279(6.5)$ & $116(6.7)$ \\
\hline Coronary artery disease $(n, \%)$ & $511(12.0)$ & $209(12.0)$ \\
\hline Hypertension (n, \%) & $\mathrm{I}, 465(34.3)$ & $557(32.0)$ \\
\hline Cancer (n, \%) & $289(6.8)$ & $98(5.6)$ \\
\hline Depression (n, \%) & $2,21 I(5 I .8)$ & $760(43.7)$ \\
\hline
\end{tabular}

Notes: aSample size represents the number of member-month observations rather than the number of unique members; ${ }^{b}$ measured on a per-I,000 members-per-month basis; 'sample restricted to member-months for which patients had Geisinger Health Plan prescription drug coverage (pre-MPP, n=2,984; post-MPP, $n=1,320$ ).

Abbreviations: MPP, Multispecialty Pain Program; IP, inpatient; ED, emergency department; PCP, primary care provider; OP, outpatient; PMPM, per-member-permonth; Rx, prescription.

Table 3 MPP impact on total cost of care

\begin{tabular}{|c|c|c|c|c|c|c|c|c|c|c|}
\hline \multirow{2}{*}{$\begin{array}{l}\text { Length } \\
\text { of MPP } \\
\text { exposure }\end{array}$} & \multicolumn{5}{|c|}{$\begin{array}{l}\text { \$ Total allowed (medical + Rx per-member-per- } \\
\text { month) }\end{array}$} & \multicolumn{5}{|c|}{ \$ Medical allowed (per-member-per-month) } \\
\hline & $\mathbf{N}^{\mathbf{a}}$ & Observed & Expected & Difference & $P$-value & $\mathbf{N}^{\mathbf{a}}$ & Observed & Expected & Difference & $P$-value \\
\hline I-6 Months & 575 & 1,678 & 2,505 & -827 & 0.003 & 575 & $\mathrm{I}, 352$ & 2,223 & -870 & 0.002 \\
\hline 7-12 Months & 482 & 2,104 & 2,580 & -475 & 0.213 & 482 & $\mathrm{I}, 740$ & 2,334 & -594 & 0.113 \\
\hline$>12$ Months & 682 & 2,248 & 2,815 & -567 & 0.306 & 682 & $\mathrm{I}, 854$ & 2,575 & -721 & 0.181 \\
\hline All Months & 1,739 & 2,021 & 2,775 & -754 & 0.014 & 1,739 & 1,659 & 2,505 & -846 & 0.006 \\
\hline
\end{tabular}

Note: aSample size represents the number of member-month observations rather than the number of unique members.

Abbreviation: MPP, Multispecialty Pain Program; Rx, prescription.

filled opioid prescriptions (Table 5), a similar trend of initial reduction and overall reduction in the opioid prescription fill frequency was also observed.

\section{Discussion}

To our knowledge, this is the first study that examined the longterm (12+ months of follow-up) impact of a comprehensive outpatient multidisciplinary program designed to treat chronic pain using actual health insurance claims data of the treated patients. The results suggest that, while the initial impact of the program during the first 6-month period following the MPP enrollment was consistent with the expectation that MPP has led to reductions in care utilization and total cost of care, a more in-depth analysis of the data is necessary to understand the post-intervention dynamics of the program impact over time. The statistically significant reductions in the use of high-end diagnostic imaging and the corresponding reductions in total medical cost of care provide empirical evidence supporting the notion that MPP has had the desired effect of altering patients' care-seeking behaviors in positive ways, as MPP 
Table 4 MPP impact on acute care utilization

\begin{tabular}{|c|c|c|c|c|c|c|c|c|c|c|}
\hline \multirow{2}{*}{$\begin{array}{l}\text { Length } \\
\text { of MPP } \\
\text { exposure }\end{array}$} & \multicolumn{5}{|c|}{$\begin{array}{l}\text { Acute inpatient admits (per-1,000 members-per } \\
\text { month) }\end{array}$} & \multicolumn{5}{|c|}{$\begin{array}{l}\text { Emergency department visits (per-I,000 members- } \\
\text { per-month) }\end{array}$} \\
\hline & $\mathbf{N}^{\mathbf{a}}$ & Observed & Expected & Difference & $P$-value & $\mathbf{N}^{\mathrm{a}}$ & Observed & Expected & Difference & $P$-value \\
\hline I-6 Months & 575 & 23 & 44 & -21 & 0.094 & 575 & 144 & 178 & -34 & 0.176 \\
\hline $7-12$ Months & 482 & 27 & 46 & -19 & 0.219 & 482 & 118 & 152 & -34 & 0.264 \\
\hline$>12$ Months & 682 & 41 & 45 & -4 & 0.846 & 682 & 152 & 171 & -19 & 0.663 \\
\hline All Months & 1,739 & 31 & 51 & -20 & 0.086 & 1,739 & 140 & 173 & -33 & 0.173 \\
\hline
\end{tabular}

Note: a Sample size represents the number of member-month observations rather than the number of unique members.

Abbreviation: MPP, Multispecialty Pain Program.

Table 5 MPP impact on high-end diagnostic imaging and opioid prescription use

\begin{tabular}{|c|c|c|c|c|c|c|c|c|c|c|}
\hline \multirow{2}{*}{$\begin{array}{l}\text { Length } \\
\text { of MPP } \\
\text { exposure }\end{array}$} & \multicolumn{5}{|c|}{$\begin{array}{l}\text { High-end diagnostic imaging (per-I,000 members-per- } \\
\text { month) }\end{array}$} & \multicolumn{5}{|c|}{$\begin{array}{l}\text { Count of opioid prescription (per- } 1,000 \text { members-per- } \\
\text { month) }\end{array}$} \\
\hline & $\mathbf{N}^{\mathbf{a}}$ & Observed & Expected & Difference & $P$-value & $\mathbf{N}^{\mathrm{a}}$ & Observed & Expected & Difference & $P$-value \\
\hline I-6 Months & 575 & 59 & 112 & -53 & 0.008 & 451 & 0.72 & 0.83 & -0.11 & 0.154 \\
\hline $7-12$ Months & 482 & 68 & 115 & -46 & 0.132 & 372 & 0.84 & 0.83 & 0.01 & 0.892 \\
\hline$>12$ Months & 682 & 109 & 125 & -16 & 0.653 & 497 & 0.90 & 0.99 & -0.10 & 0.494 \\
\hline All Months & 1,739 & 81 & 133 & -52 & 0.015 & 1,320 & 0.82 & 0.90 & -0.08 & 0.369 \\
\hline
\end{tabular}

Note: ${ }^{a}$ Sample size represents the number of member-month observations rather than the number of unique members.

Abbreviation: MPP, Multispecialty Pain Program.

patients appear to have used less of discretionary care such as high-end imaging. To lesser extents, this is further supported by the non-statistically significant reductions in ED visits, opioid prescription fill frequencies, and acute inpatient admission rates. However, the question of why this initial impact did not sustain in later follow-up periods remains unanswered in this study and is a topic of future research.

The most significant limitation of this study is the lack of direct measure of pain-related patient health outcomes that may be impacted by MPP (eg, pain severity). This study has considered only the outcomes that are economic and quantitative in nature and has ignored any clinical and qualitative outcomes. Unfortunately, the current literature provides little guidance on how to objectively and reliably capture the latter category of outcome measures across such a heterogeneous population of chronic pain patients as the one treated by MPP. ${ }^{4,14}$ Consequently, a true cost-effectiveness study of the MPP is not feasible with the available data. However, the results reported in this study are at least consistent with the expectation that MPP is likely to have improved the patient health outcomes at least in the short term.

This study is further subject to additional limitations. First, this study has relied on observational data collected from administrative data sources, rather than data collected via a randomized control trial; as such, causality cannot be established. As shown in Table 2, there appears to be some important underlying differences that may confound the association between MPP enrollment and the dependent variables of interest. This study has attempted to reduce any unobserved bias using an advance statistical adjustment technique, but ultimately it is not possible to determine the magnitude of this potential bias in the estimates using the available data. For instance, due to natural disease progression, which is unobserved in the data, the estimated MPP impact may be biased. If such were the case, however, our estimates are likely to be biased toward zero - ie, the estimated impact in this study would underestimate the true impact because natural disease progression implies worsening health conditions and therefore higher care utilization and cost.

Second, the sample size is limited, especially in the comparison group. A new study based on a larger sample size with longer follow-up may yield more precise and consistent estimates of the impact. The small sample size also implies that the representativeness and generalizability of the results are unclear. For instance, there may be market and patient characteristics unique to Geisinger and its patient population that may limit the generalizability of the findings in other settings.

\section{Conclusion}

Patients enrolled in MPP were less likely to use expensive diagnostic imaging and experienced fewer hospitalizations, resulting in total cost of care savings. These findings are 
consistent with the expectation that MPP improves health outcomes among patients suffering from chronic pain.

\section{Acknowledgments}

The abstract of this paper was presented at the 24th Annual Health Care Systems Research Network Conference, April 11-13, 2018, Minneapolis, Minnesota, USA, as an oral presentation with interim findings. The abstract has been published online, doi: 10.17294/2330-0698.1630.

\section{Disclosure}

The authors report no conflicts of interest in this work.

\section{References}

1. Gaskin DJ, Richard P. The economic costs of pain in the United States. J Pain. 2012;13(8):715-724.

2. Institute of Medicine. Relieving Pain in America: A Blueprint for Transforming Prevention, Care, Education, and Research. Washington, DC: The National Academies Press; 2011.

3. Nahin RL. Estimates of pain prevalence and severity in adults: United States, 2012. J Pain. 2015;16(8):769-780.

4. Malhotra A, Mackey S. Outcomes in pain medicine: a brief review. Pain Ther. 2012;1(1):5.
5. Dansie EJ, Turk DC. Assessment of patients with chronic pain. Br J Anaesth. 2013;111(1):19-25.

6. Steglitz J, Buscemi J, Ferguson MJ. The future of pain research, education, and treatment: a summary of the IOM report "Relieving pain in America: a blueprint for transforming prevention, care, education, and research". Transl Behav Med. 2012;2(1):6-8.

7. Dorflinger L, Kerns RD, Auerbach SM. Providers' roles in enhancing patients' adherence to pain self management. Transl Behav Med. 2013;3(1):39-46.

8. Fishman SM, Young HM, Lucas Arwood E, et al. Core competencies for pain management: results of an interprofessional consensus summit. Pain Med. 2013;14(7):971-981.

9. Doleys DM. Chronic Pain as a Hypothetical Construct: A Practical and Philosophical Consideration. Front Psychol. 2017;8:664.

10. Darnall BD, Sturgeon JA, Kao MC, Hah JM, Mackey SC. From Catastrophizing to Recovery: a pilot study of a single-session treatment for pain catastrophizing. J Pain Res. 2014;7:219-226.

11. Moore SK, Guarino H, Acosta MC, et al. Patients as collaborators: using focus groups and feedback sessions to develop an interactive, web-based self-management intervention for chronic pain. Pain Med. 2013;14(11):1730-1740.

12. Reid MC, Eccleston C, Pillemer K. Management of chronic pain in older adults. BMJ. 2015;350:h532.

13. Clark T, Wakim JC, Noe C. Getting "Unstuck": A Multi-Site Evaluation of the Efficacy of an Interdisciplinary Pain Intervention Program for Chronic Low Back Pain. Healthcare. 2016;4(2):33.

14. Younger J, Mccue R, Mackey S. Pain outcomes: a brief review of instruments and techniques. Curr Pain Headache Rep. 2009;13(1):39-43. 


\section{Supplementary materials}

Regression model specification

$\mathrm{Y}_{i t}=\alpha_{0}+\alpha_{1}$ MPP_Exp ${ }_{i t}+\alpha_{2} \mathrm{X}_{\mathrm{it}}+\mathrm{v}_{i}+\varepsilon_{i t}$

$\mathrm{Y}_{\mathrm{it}}=$ dependent variable (cost of care or utilization) for member $i$ at time $t$

MPP_Exp ${ }_{i t}=$ a set of indicator variables denoting the time $t$ in intervals since member $i$ 's MPP enrollment

$\mathrm{X}_{\mathrm{it}}=\mathrm{a}$ vector of time-varying characteristics for member $i$ at time $t$ (ie, health plan type, age, calendar year, number of comorbid conditions, etc)

$\mathrm{v}_{\mathrm{i}}=$ fixed effect for member $i$ (a set of indicator variables corresponding to each member $i$ in the sample)

$\varepsilon_{\mathrm{it}}=$ error term for member $i$ at time $t$
The coefficients of interest are denoted by $\alpha_{1}$ for all the dependent variables. The above-mentioned equation is estimated via generalized linear models with log link and gamma distribution if cost of care was the dependent variable; for all other dependent variables that are count data (ie, inpatient admission, emergency department visits, etc), the equation was estimated via Poisson model. In all cases, clustered standard errors were reported, because there were repeated observations of the same patients in the data over time, and therefore the error term $\varepsilon_{i t}$ is likely to be correlated within the same patient.

Full regression outputs

Table SI Full regression outputs for cost of care variables (Generalized linear model with log link and gamma distribution)

\begin{tabular}{|c|c|c|c|c|c|c|}
\hline \multirow{3}{*}{$\begin{array}{l}\text { Covariate* } \\
\text { Post-MPP: I-6 months }\end{array}$} & \multicolumn{3}{|c|}{ Total cost (medical + Rx) } & \multicolumn{3}{|c|}{ Total medical cost } \\
\hline & \multirow{2}{*}{$\begin{array}{l}\text { Coefficient } \\
-0.40\end{array}$} & \multicolumn{2}{|c|}{$95 \% \mathrm{Cl}$} & \multirow{2}{*}{$\begin{array}{l}\text { Coefficient } \\
-0.50\end{array}$} & \multicolumn{2}{|c|}{$95 \% \mathrm{Cl}$} \\
\hline & & -0.66 & -0.14 & & -0.81 & -0.18 \\
\hline Post-MPP: 7-12 months & -0.20 & -0.52 & 0.12 & -0.29 & -0.66 & 0.07 \\
\hline Post-MPP: $>12$ months & -0.22 & -0.66 & 0.21 & -0.33 & -0.81 & 0.15 \\
\hline Medicare & 0.29 & -0.34 & 0.92 & 0.66 & -0.10 & 1.42 \\
\hline Commercial & 0.71 & 0.33 & 1.09 & 0.87 & $0.4 I$ & 1.33 \\
\hline Has GHP Rx coverage & 0.41 & -0.09 & 0.92 & 0.18 & -0.37 & 0.73 \\
\hline Age $40-54$ years & 0.01 & -0.70 & 0.73 & 0.04 & -0.83 & 0.92 \\
\hline Age $55-69$ years & 1.17 & 0.15 & 2.19 & 0.92 & -0.34 & 2.17 \\
\hline Age $>69$ years & 1.49 & 0.34 & 2.63 & 1.15 & -0.23 & 2.54 \\
\hline In a medical home & -0.18 & -0.42 & 0.06 & -0.14 & -0.41 & 0.13 \\
\hline \# Comorbidity: I & 0.03 & -0.23 & 0.28 & 0.00 & -0.29 & 0.29 \\
\hline \# Comorbidity: 2 & 0.06 & -0.20 & 0.32 & 0.02 & -0.27 & 0.31 \\
\hline \# Comorbidity: 3 & 0.15 & -0.19 & 0.48 & 0.09 & -0.29 & 0.48 \\
\hline \# Comorbidity: 4+ & 0.07 & -0.23 & 0.37 & 0.05 & -0.34 & 0.45 \\
\hline Year 2014 & 0.19 & -0.02 & 0.40 & 0.17 & -0.06 & 0.40 \\
\hline Year 2016 & 0.50 & 0.21 & 0.79 & 0.49 & 0.16 & 0.82 \\
\hline Year 2017 & 0.37 & 0.00 & 0.74 & 0.36 & -0.05 & 0.77 \\
\hline
\end{tabular}

Note: *Patient fixed effects omitted for brevity.

Abbreviations: MPP, Multidisciplinary Pain Program; Rx, prescription; GHP, Geisinger Health Plan. 
Table S2 Full regression outputs for acute care utilization variables (Poisson model)

\begin{tabular}{|c|c|c|c|c|c|c|}
\hline \multirow{3}{*}{$\begin{array}{l}\text { Covariate* } \\
\text { Post-MPP: I-6 months }\end{array}$} & \multicolumn{3}{|c|}{ Acute inpatient admits } & \multicolumn{3}{|c|}{ Emergency department visit } \\
\hline & \multirow{2}{*}{$\begin{array}{l}\text { Coefficient } \\
-0.66\end{array}$} & \multicolumn{2}{|c|}{$95 \% \mathrm{Cl}$} & \multirow{2}{*}{$\begin{array}{l}\text { Coefficient } \\
-0.21 \\
\end{array}$} & \multicolumn{2}{|c|}{$95 \% \mathrm{Cl}$} \\
\hline & & -1.43 & 0.11 & & -0.52 & 0.10 \\
\hline Post-MPP: 7-12 months & -0.52 & -1.36 & 0.31 & -0.25 & -0.69 & 0.19 \\
\hline Post-MPP: $>12$ months & -0.09 & -0.96 & 0.79 & -0.12 & -0.64 & 0.41 \\
\hline Medicare & $2 \mathrm{~d} 0.3 \mathrm{I}$ & 18.83 & 21.79 & -0.70 & -1.94 & 0.54 \\
\hline Commercial & 0.00 & -0.99 & 0.99 & 0.02 & -0.59 & 0.64 \\
\hline Has GHP Rx coverage & -0.23 & -1.54 & 1.09 & -0.49 & -1.16 & 0.17 \\
\hline Age $40-54$ years & 0.76 & $-|.3|$ & 2.83 & 0.25 & -0.63 & 1.13 \\
\hline Age $55-69$ years & 0.92 & -1.55 & 3.39 & 0.32 & -0.74 & 1.38 \\
\hline Age $>69$ years & 0.76 & -2.17 & 3.69 & 2.09 & -0.05 & 4.24 \\
\hline In a medical home & -0.03 & -0.79 & 0.72 & -0.17 & -0.48 & 0.13 \\
\hline \# Comorbidity: I & -0.55 & -1.15 & 0.05 & -0.26 & -0.60 & 0.09 \\
\hline \# Comorbidity: 2 & 0.17 & -0.55 & 0.88 & -0.08 & -0.52 & 0.37 \\
\hline \# Comorbidity: 3 & 0.32 & -0.54 & 1.18 & -0.21 & -0.88 & 0.47 \\
\hline \# Comorbidity: 4+ & -0.17 & -0.94 & 0.61 & 0.66 & 0.27 & 1.04 \\
\hline Year 2014 & -0.16 & -0.70 & 0.38 & -0.31 & -0.63 & 0.02 \\
\hline Year 2016 & 0.44 & -0.23 & 1.11 & -0.10 & -0.44 & 0.24 \\
\hline Year 2017 & 0.05 & -0.84 & 0.93 & 0.09 & -0.39 & 0.57 \\
\hline
\end{tabular}

Note: *Patient fixed effects omitted for brevity.

Abbreviations: MPP, Multidisciplinary Pain Program; Rx, prescription; GHP, Geisinger Health Plan.

Table S3 Full regression outputs for diagnostic imaging and opioid medication utilization variables (Poisson model)

\begin{tabular}{|c|c|c|c|c|c|c|}
\hline \multirow{3}{*}{$\begin{array}{l}\text { Covariate* } \\
\text { Post-MPP: I-6 months }\end{array}$} & \multicolumn{3}{|c|}{ High-end diagnostic imaging } & \multicolumn{3}{|c|}{ Opioid prescription } \\
\hline & \multirow{2}{*}{$\begin{array}{l}\text { Coefficient } \\
-0.64\end{array}$} & \multicolumn{2}{|c|}{$95 \% \mathrm{Cl}$} & \multirow{2}{*}{$\begin{array}{l}\text { Coefficient } \\
-0.14\end{array}$} & \multicolumn{2}{|c|}{$95 \% \mathrm{Cl}$} \\
\hline & & -1.11 & -0.16 & & -0.33 & 0.05 \\
\hline Post-MPP: 7-12 months & -0.52 & -1.19 & 0.16 & 0.02 & -0.22 & 0.25 \\
\hline Post-MPP: $>12$ months & -0.14 & -0.74 & 0.46 & -0.10 & -0.39 & 0.19 \\
\hline Medicare & 0.16 & -0.38 & 0.70 & 0.94 & -0.59 & 2.47 \\
\hline Commercial & 0.26 & -0.32 & 0.85 & -0.23 & -1.40 & 0.93 \\
\hline Has GHP Rx coverage & 1.36 & 0.26 & 2.46 & (omitted) & & \\
\hline Age $40-54$ years & -0.55 & -2.58 & $\mathrm{I} .48$ & 0.01 & -0.72 & 0.73 \\
\hline Age $55-69$ years & -0.25 & -2.57 & 2.07 & 0.28 & -0.59 & 1.15 \\
\hline Age $>69$ years & -0.95 & -3.52 & 1.62 & 0.57 & -0.60 & 1.75 \\
\hline In a medical home & 0.29 & -0.29 & 0.87 & -0.01 & -0.29 & 0.26 \\
\hline \# Comorbidity: I & -0.09 & -0.67 & 0.50 & 0.16 & -0.06 & 0.38 \\
\hline \# Comorbidity: 2 & 0.03 & -0.59 & 0.65 & -0.11 & -0.29 & 0.07 \\
\hline \# Comorbidity: 3 & 0.27 & -0.39 & 0.93 & -0.14 & -0.30 & 0.01 \\
\hline \# Comorbidity: 4+ & 0.72 & 0.13 & 1.31 & -0.01 & -0.22 & 0.20 \\
\hline Year 2014 & 0.12 & -0.27 & 0.51 & 0.03 & -0.10 & 0.15 \\
\hline Year 2016 & 0.07 & -0.33 & 0.48 & 0.00 & -0.19 & 0.19 \\
\hline Year 2017 & 0.19 & -0.39 & 0.78 & 0.05 & -0.20 & 0.30 \\
\hline
\end{tabular}

Note: *Patient fixed effects omitted for brevity.

Abbreviations: MPP, Multidisciplinary Pain Program; Rx, prescription; GHP, Geisinger Health Plan.

Journal of Pain Research

\section{Publish your work in this journal}

The Journal of Pain Research is an international, peer reviewed, open access, online journal that welcomes laboratory and clinical findings in the fields of pain research and the prevention and management of pain. Original research, reviews, symposium reports, hypothesis formation and commentaries are all considered for publication.
The manuscript management system is completely online and includes a very quick and fair peer-review system, which is all easy to use. Visit http://www.dovepress.com/testimonials.php to read real quotes from published authors. 